\title{
Sunlight-driven nitrate loss records Antarctic surface mass balance
}

Pete D. Akers ( $\square$ pete.d.akers@gmail.com )

Université Grenoble Alpes, CNRS, IRD, Grenoble INP, IGE, Grenoble, France https://orcid.org/0000-00022266-5551

\section{Joël Savarino}

Université Grenoble Alpes, CNRS, IRD, Grenoble INP, IGE, Grenoble, France

\section{Nicolas Caillon}

Université Grenoble Alpes, CNRS, IRD, Grenoble INP, IGE, Grenoble, France

\section{Aymeric P. M. Servettaz}

Japan Agency for Marine-Earth Science and Technology, Yokosuka, Japan

\section{Emmanuel Le Meur}

Université Grenoble Alpes, CNRS, IRD, Grenoble INP, IGE, Grenoble, France

\section{Olivier Magand}

Université Grenoble Alpes, CNRS, IRD, Grenoble INP, IGE, Grenoble, France

\section{Jean Martins}

Université Grenoble Alpes, CNRS, IRD, Grenoble INP, IGE, Grenoble, France

\section{Cécile Agosta}

Laboratoire des Sciences du Climat et de I'Environnement, LSCE-IPSL, CEA-CNRS-UVSQ, Université Paris-

Saclay, Gif-sur-Yvette, France https://orcid.org/0000-0003-4091-1653

\section{Peter Crockford}

Department of Earth and Planetary Sciences, Weizmann Institute of Science, Rehovot, Israel;

Department of Earth and Planetary Sciences, Harvard University, Cambridge, MA, USA

\section{Kanon Kobayashi}

Department of Chemical Science and Engineering, Tokyo Institute of Technology, Yokohama, Japan

\section{Shohei Hattori}

Department of Chemical Science and Engineering, Tokyo Institute of Technology, Yokohama, Japan; International Center for Isotope Effects Research, Nanjing University, Nanjing, China

\section{Mark Curran}

Australian Antarctic Division, Department of Agriculture, Water and Environment, Kingston, Tasmania, Australia; Australian Antarctic Program Partnership, Institute of Marine and Antarctic Studies, University of Tasmania, Hobart, Tasmania, Australia

\section{Tas van Ommen}

Australian Antarctic Division, Department of Agriculture, Water and Environment, Kingston, Tasmania, Australia; Australian Antarctic Program Partnership, Institute of Marine and Antarctic Studies, University 
of Tasmania, Hobart, Tasmania, Australia https://orcid.org/0000-0002-2463-1718

\section{Lenneke Jong}

Australian Antarctic Division, Department of Agriculture, Water and Environment, Kingston, Tasmania, Australia; Australian Antarctic Program Partnership, Institute of Marine and Antarctic Studies, University of Tasmania, Hobart, Tasmania, Australia

\section{Jason L. Roberts}

Australian Antarctic Division, Department of Agriculture, Water and Environment, Kingston, Tasmania, Australia; Australian Antarctic Program Partnership, Institute of Marine and Antarctic Studies, University of Tasmania, Hobart, Tasmania, Australia

\section{Article}

Keywords:

Posted Date: February 8th, 2022

DOI: https://doi.org/10.21203/rs.3.rs-1307003/v1

License: (c) (1) This work is licensed under a Creative Commons Attribution 4.0 International License. Read Full License

Version of Record: A version of this preprint was published at Nature Communications on July 25th, 2022. See the published version at https://doi.org/10.1038/s41467-022-31855-7. 


\section{Sunlight-driven nitrate loss records Antarctic surface mass balance}

Authors: Pete D. Akers ${ }^{1 *}$, Joël Savarino ${ }^{1 *}$, Nicolas Caillon ${ }^{1}$, Aymeric P. M. Servettaz ${ }^{2}$, Emmanuel Le Meur ${ }^{1}$, Olivier Magand ${ }^{1}$, Jean Martins ${ }^{1}$, Cécile Agosta ${ }^{3}$, Peter Crockford ${ }^{4,5}$, Kanon Kobayashi $^{6}$, Shohei Hattori ${ }^{6,7}$, Mark Curran ${ }^{8,9}$, Tas van Ommen ${ }^{8,9}$, Lenneke Jong ${ }^{8,9}$, Jason L. Roberts 8,9

\section{Affiliations:}

${ }^{1}$ Université Grenoble Alpes, CNRS, IRD, Grenoble INP, IGE, Grenoble, France.

${ }^{2}$ Japan Agency for Marine-Earth Science and Technology, Yokosuka, Japan.

${ }^{3}$ Laboratoire des Sciences du Climat et de l'Environnement, LSCE-IPSL, CEA-CNRSUVSQ, Université Paris-Saclay, Gif-sur-Yvette, France.

${ }^{4}$ Department of Earth and Planetary Sciences, Weizmann Institute of Science, Rehovot, Israel.

${ }^{5}$ Department of Earth and Planetary Sciences, Harvard University, Cambridge, MA, USA.

${ }^{6}$ Department of Chemical Science and Engineering, Tokyo Institute of Technology, Yokohama, Japan.

${ }^{7}$ International Center for Isotope Effects Research, Nanjing University, Nanjing, China.

${ }^{8}$ Australian Antarctic Division, Department of Agriculture, Water and Environment, Kingston, Tasmania, Australia.

${ }^{9}$ Australian Antarctic Program Partnership, Institute of Marine and Antarctic Studies, University of Tasmania, Hobart, Tasmania, Australia.

*Correspondence to: pete-akers@univ-grenoble-alpes.fr; joel.savarino@cnrs.fr

\section{Abstract:}

Standard proxies for reconstructing surface mass balance (SMB) in Antarctic ice cores are often inaccurate or coarsely resolved when applied to more complicated environments away from dome summits. Here, we propose an alternative SMB proxy based on photolytic fractionation of nitrogen isotopes in nitrate observed at 114 sites throughout East Antarctica. Applying this proxy approach to nitrate in a shallow core drilled at a moderate SMB site (Aurora Basin North), we reconstruct 700 years of SMB changes that agree well with changes estimated from ice core density and upstream surface topography. For the undersampled transition zones between dome summits and the coast, this proxy can considerably 
expand our SMB records by providing high-resolution SMBs that better reflect the local environment and are easier to sample than existing techniques.

One Sentence Summary: Nitrate isotopes offer a new way to track past and present changes in Antarctic snowfall and ice sheet mass balance.

Main Text: Antarctica holds a critical role in the Earth's hydrosphere, providing long-term storage of 27 million $\mathrm{km}^{3}$ of ice ${ }^{1}$ and impacting global ocean and atmosphere circulation through its albedo, topography, export of calved glacial ice, and function as an atmospheric heat $\sin ^{2-5}$. Since even small shifts in the surface mass balance (SMB) across Antarctic ice sheets can redistribute huge masses of water between the cryosphere, ocean, and atmosphere, a clear understanding of how its SMB has responded to past climate change is crucial for calibrating forecast models of the global environment and properly interpreting ice cores ${ }^{6-10}$. Despite this pressing importance, a comprehensive understanding of past SMB changes in Antarctica is limited by insufficient long-term records for sites between of the wet coastal periphery and dry dome summits.

Reconstructing SMBs in this moderate SMB transition zone can be challenging with existing SMB proxies. Ice density-based reconstructions become less effective and more uncertain with depth due to thinning and deformation of ice layers ${ }^{11}$, while the frequent minor damage and breakage of cores during the drilling process can make accurate physical measurements of mass and volume challenging. Water isotopes $\left(\delta^{2} \mathrm{H}\right.$ or $\left.\delta^{18} \mathrm{O}\right)$ can be used as a proxy temperature to derive snow accumulation through water vapor saturation ${ }^{10}$, but this approach does not account for wind-driven transport and sublimation of surface snow at warmer and lower elevation sites ${ }^{12-14}$. Additionally, water isotopes reflect many environmental factors other than temperature, such as atmospheric circulation changes, which can lead to large uncertainty and/or bias in reconstructed SMBs ${ }^{15,16}$. There is thus a strong need for alternative 
proxies that better record local conditions to provide SMB estimates for paleoclimate reconstructions and ice sheet models.

Here, we present one such independent SMB proxy based on photolysis-induced changes in the ${ }^{15} \mathrm{~N} /{ }^{14} \mathrm{~N}$ ratio $\left(\delta^{15} \mathrm{~N}\right.$, defined as $\delta=\frac{{ }^{15} \mathrm{~N} /{ }^{14} \mathrm{~N}_{\text {sample }}}{{ }^{15} \mathrm{~N} /{ }^{14} \mathrm{~N}_{\text {standard }}}-1$, relative to the $\mathrm{N}_{2}$-air standard $)$ of nitrate $\left(\mathrm{NO}_{3}{ }^{-}\right)$(Figure 1). Naturally deposited on the Antarctic ice sheet surface as the end product of the atmospheric oxidation of reactive nitrogen ${ }^{17-20}, \mathrm{NO}_{3}{ }^{-}$within the Antarctic snowpack can be photolytically converted to gaseous nitrogen oxides $\left(\mathrm{NO}_{\mathrm{x}}=\mathrm{NO}+\mathrm{NO}_{2}\right)$ when exposed to ultraviolet light $(\lambda=290-350 \mathrm{~nm})$. Because ${ }^{14} \mathrm{NO}_{3}{ }^{-}$is more readily photolyzed than ${ }^{15} \mathrm{NO}_{3}$, the $\delta^{15} \mathrm{~N}_{\mathrm{NO}}$ of $\mathrm{NO}_{3}{ }^{-}$remaining in the snow will increase from its initial depositional value of $\approx-20$ to $+20 \%$ to values as high as $+400 \%{ }^{19-26}$ as the isotopically lighter photolytic $\mathrm{NO}_{\mathrm{x}}$ is ventilated and lost to the atmosphere. Although $\mathrm{NO}_{3}{ }^{-}$ can also be lost through $\mathrm{HNO}_{3}$ volatilization, we interpret $\delta^{15} \mathrm{~N}_{\mathrm{NO}}$ arc solely through photolysis as volatilization does not strongly fractionate $\mathrm{NO}_{3}{ }^{-}$and is a very minor component of $\mathrm{NO}_{3}{ }^{-}$loss outside of the warmest coastal zones ${ }^{22,27,28}$. Additionally, while the oxygen in $\mathrm{NO}_{3}{ }^{-}$also undergoes isotopic fractionation through photolysis, its interpretation is complicated by isotopic interactions with snow and water vapor ${ }^{22,23,29}$ and is not further discussed here. 


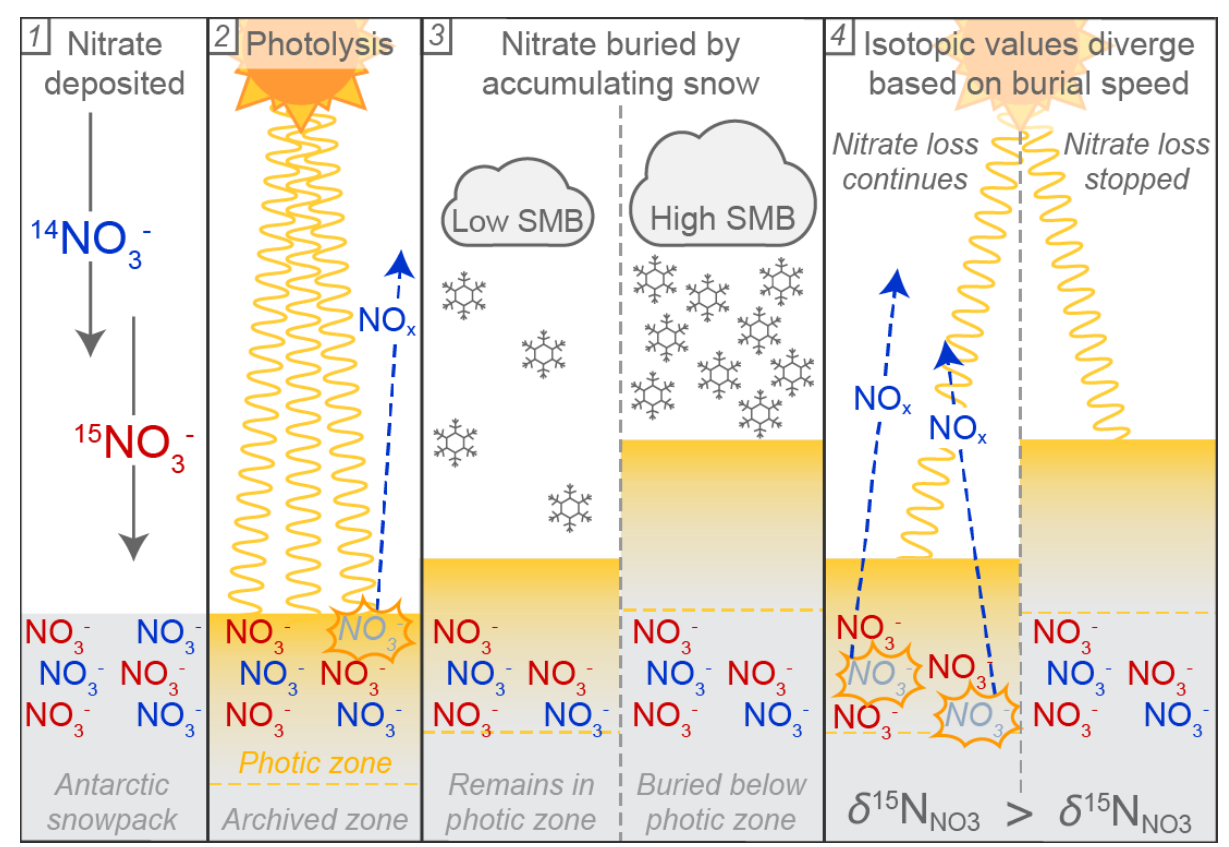

Figure 1. Schematic diagram illustrating that SMB and $\delta^{15} \mathrm{~N}_{\mathrm{NO} 3 \text { arc }}$ values covary due to photolytic $\mathrm{NO}_{3}{ }^{-}$mass loss. After $\mathrm{NO}_{3}{ }^{-}$containing either ${ }^{14} \mathrm{~N}$ (blue) and ${ }^{15} \mathrm{~N}$ (red) is deposited on the Antarctic snowpack surface (1), sunlight in the photic zone can trigger photolysis of $\mathrm{NO}_{3}{ }^{-}$that favors $\mathrm{NO}_{3}{ }^{-}$with a ${ }^{14} \mathrm{~N}$ atom, which leaves the residual $\mathrm{NO}_{3}{ }^{-}$enriched in ${ }^{15} \mathrm{~N}(2)$. Because sites with lower SMBs will accumulate less snow over a given period of time than high SMB sites (3), the $\mathrm{NO}_{3}{ }^{-}$at lower SMB sites will remain in the photic zone longer, experience more photolytic mass loss before burial in the archived zone, and have higher $\delta^{15} \mathrm{~N}_{\mathrm{NO} \text { arc }}$ values (4).

Photolysis is limited to the depth where light penetrates and initiates photochemical reactions, and so the snowpack can be divided into an uppermost photic zone (generally $10-100 \mathrm{~cm}$ in East Antarctica) and a deeper archived zone ${ }^{29-33}$. Photolysis and the resulting isotopic fractionation of $\mathrm{NO}_{3}{ }^{-}$cease once snowfall buries $\mathrm{NO}_{3}{ }^{-}$beneath the photic zone, and the $\delta^{15} \mathrm{~N}_{\mathrm{NO} 3}$ value of the buried $\mathrm{NO}_{3}{ }^{-}\left(\delta^{15} \mathrm{~N}_{\mathrm{NO} 3 a r c}\right)$ is assumed to be preserved indefinitely in glacial ice $22,23,29,30$. The final $\delta^{15} \mathrm{~N}_{\mathrm{NO} 3 a r c}$ value reflects the total sum of photolysis inducing radiation experienced by $\mathrm{NO}_{3}{ }^{-}$during the burial process, which, assuming stable insolation and photic zone depth, is itself determined by the rate at which the $\mathrm{NO}_{3}{ }^{-}$is buried and thus inversely related to $\mathrm{SMB}^{17,23,26,34}$. Modeling (Supplementary Text 1) and field observations support SMB as the primary driver of spatial variability in $\delta^{15} \mathrm{~N}_{\mathrm{NO}}$ arc values. Based on a new 
simplified theoretical framework (Methods, Supplementary Text 1), this relationship can be expressed as:

$\ln \left(\delta^{15} N_{N O 3 a r c}+1\right)=\frac{A}{S M B}+B$

where the regression coefficients $A$ and $B$ are parameters that subsume constants and linearly co-varying variables associated with photolytic and fractionation processes. The inverse function of Eq. (1) can then be used as a transfer function to reconstruct SMBs from $\delta^{15} \mathrm{~N}_{\mathrm{NO}}$ arc values $\left(\mathrm{SMB}_{\delta 15 \mathrm{~N}}\right)$.

\section{Results: $\mathrm{SMB}_{\delta 15 \mathrm{~N}}$ relationship and spatial applicability}

To obtain parameter estimates for Eq. (1), we sampled $\mathrm{NO}_{3}{ }^{-}$in snow and firn from 92 East Antarctic shallow pits and cores that are newly reported here. Combined with 43 previously published $\delta^{15} \mathrm{~N}_{\mathrm{NO} 3 a r c}$ samples ${ }^{21-23,26,29,35}$, this constitutes a database of 135 total $\delta^{15} \mathrm{~N}_{\mathrm{NO}}$ arc values representing 114 distinct sites across East Antarctica (Figure 2a). These $\delta^{15} \mathrm{~N}_{\text {NO3arc }}$ data were spatially paired with local SMBs either observed directly onsite (SMBground) or as an output from the Modèle Atmosphérique Régional (MAR) using ERA-interim reanalysis data $^{12}$ and adjusted for a dry-site bias (SMB adjMAR) (Methods, Supplementary Text 2). The sites in our database cover a comprehensive range of East Antarctic SMBs, from 20-30 kg m ${ }^{2} \mathrm{a}^{-1}$ at dome summits on the high plateau to $>300 \mathrm{~kg} \mathrm{~m}^{-2} \mathrm{a}^{-1}$ for sites on the coastal periphery. 

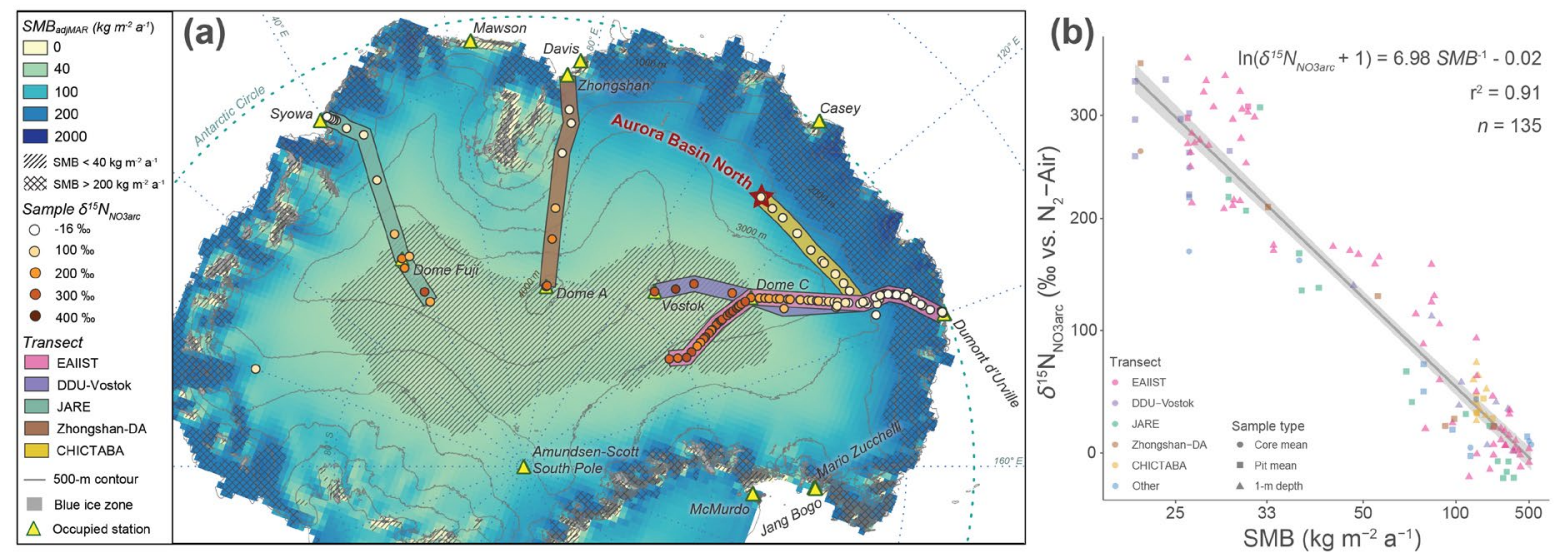

Figure 2. A) Map of East Antarctic sites sampled for $\delta^{15} \mathrm{~N}_{\mathrm{NO} \text { arc }}$ along different scientific and logistic transect routes $^{36}$. The SMBs were modeled by MAR ${ }^{12}$ and adjusted for dry site bias (see Methods). Regions with SMBs less than or greater than $40-200 \mathrm{~kg} \mathrm{~m}^{-2} \mathrm{a}^{-1}$ (i.e., the SMB range targeted by the proxy described here) are illustrated with hatching and crosshatching, respectively. Preservation of $\mathrm{NO}_{3}{ }^{-}$is not expected in blue ice zones (gray solid) due to very low or negative SMBs and wind scouring ${ }^{37}$. B) Scatter plot and linear regression of Eq. (1) using all sites in the field dataset. Note that axis labels have been converted to show simpler SMB and $\delta^{15} \mathrm{~N}_{\mathrm{NO} 3 a r c}$ values. The linear regression (gray solid line) is shown with shaded $95 \%$ confidence intervals, and regression parameters are displayed at upper right. The point colors correspond to the transect of origin shown in (a), and the point shapes correspond to the sampling method (i.e., snow core, snow pit, or 1-m depth layer).

The SMB and $\delta^{15} \mathrm{~N}_{\mathrm{NO} \text { arc }}$ in our field dataset are correlated with a high degree of confidence, producing a linear regression where $\ln \left(\delta^{15} \mathrm{~N}_{\mathrm{NO} 3 \mathrm{arc}}+1\right)=6.98 \pm 0.19 \mathrm{SMB}^{-1}-0.02 \pm 0.01$ (Figure $2 \mathrm{~b}, r^{2}=0.91, p \ll 0.001, n=135$ ). This relationship is within modeled expectations (Figure S3, Supplementary Text 1) and reproduces the spatial variability of $\delta^{15} \mathrm{~N}_{\mathrm{NO} \text { arc }}$ observed throughout East Antarctica (Table S6). Although millennial-scale changes in global nitrogen dynamics and atmospheric oxidative capacity are not currently well known, the $\mathrm{SMB}_{\delta 15 \mathrm{~N}}$ proxy should be broadly applicable to Holocene-age ice as the factors parameterized in Eq. (1) have likely been relatively stable during this time (Supplementary Text 1). For pre-Holocene ice, $\delta^{15} \mathrm{~N}_{\mathrm{NO} 3 a r c}$ can still offer important insight into relative 
changes in SMB and into how nitrate dynamics varied during the dramatically different Antarctic and global environments of the Pleistocene.

While our field dataset covers sites with SMBs from 22 to $548 \mathrm{~kg} \mathrm{~m}^{-2} \mathrm{a}^{-1}$, the $\mathrm{SMB}_{\delta 15 \mathrm{~N}}$ proxy appears best suited for sites with SMBs between 40 and $200 \mathrm{~kg} \mathrm{~m}^{-2} \mathrm{a}^{-1}$. Shallow cores from very dry Dome A and Dome $\mathrm{C}$ have lower $\delta^{15} \mathrm{~N}_{\mathrm{NO}}$ arc values at $2-6 \mathrm{~m}$ below the surface than at the $\sim 1 \mathrm{~m}$ base of the photic zone, possibly because photolytic $\mathrm{NO}_{\mathrm{x}}$ can be transported downward through firn air convection and re-oxidized into $\mathrm{NO}_{3}{ }^{-}$with low $\delta^{15} \mathrm{~N}_{\mathrm{NO}}$ values (Supplementary Text 3, Figure S5). Although this phenomenon violates the foundational assumption of "locked-in" $\mathrm{NO}_{3}{ }^{-}$beneath the photic zone, we observe only it at the ultra-dry interior sites where $\mathrm{SMB}>40 \mathrm{~kg} \mathrm{~m}^{-2} \mathrm{a}^{-1}$. For sites with $\mathrm{SMB}>200 \mathrm{~kg} \mathrm{~m}^{-2} \mathrm{a}^{-1}$, the expected $140 \quad \delta^{15} \mathrm{~N}_{\mathrm{NO} 3 a r c}$ value falls within the general range of atmospheric $\delta^{15} \mathrm{~N}_{\mathrm{NO} 3}(<+20 \%$ ) because $\mathrm{NO}_{3}{ }^{-}$is buried below the photic zone in less than a year. Since more than $80 \%$ of $\mathrm{NO}_{3}{ }^{-}$is deposited during months with sunshine outside of winter polar night ${ }^{22,38}$, samples that integrate multiple years of accumulation at high SMB sites might still resolve differences in $\mathrm{SMB}$, but the greater $\mathrm{HNO}_{3}$ volatilization at these warmer and wetter sites also warrant caution due to possible interference. Additionally, the asymptotic nature of $\mathrm{SMB}^{-1}$ means that $\delta^{15} \mathrm{~N}_{\mathrm{NO} 3 \text { arc }}$ values are increasingly less sensitive to SMB changes with higher SMB values. Despite these restrictions, over $59 \%$ of Antarctica has a SMB between 40 and $200 \mathrm{~kg} \mathrm{~m}^{-2} \mathrm{a}^{-1}$ ${ }^{12}$ (Figure 2), and additional study of $\mathrm{NO}_{3}{ }^{-}$dynamics in wet and dry extremes may reveal regional adjustments that allow our proxy's SMB range to be expanded.

\section{Results: Aurora Basin North SMB reconstruction}

As a proof of concept, we applied the $\mathrm{SMB} \delta 15 \mathrm{~N}$ transfer function to $\delta^{15} \mathrm{~N}_{\mathrm{NO}}$ arc data from the 103 m deep ABN1314-103 ice core. This core was one of three drilled in the Australian 
Antarctic Program's 2013-2014 summer campaign at Aurora Basin North (ABN; $71.17^{\circ} \mathrm{S}$ $111.37^{\circ} \mathrm{E}, 2679 \mathrm{~m}$ above sea level), a site with moderate modern SMBs $\left(\approx 120 \mathrm{~kg} \mathrm{~m}^{-2} \mathrm{a}^{-1}\right)$ located midway between coastal Casey Station and the Dome C summit (Figure 2a). The $\operatorname{SMB}_{\delta 15 \mathrm{~N}}$ history reconstructed from $\mathrm{ABN} 1314-103$ covers the period from -47 to 649 years before present $(B P$, where present $=1950 \mathrm{CE})$ and has values ranging from 49 to $208 \mathrm{~kg} \mathrm{~m}^{-2}$ $\mathrm{a}^{-1}$ (Figure $3 \mathrm{a}$ ). Each $\mathrm{SMB}_{\delta 15 \mathrm{~N}}$ value integrates an average of 2.4 years of accumulation (total range: $0.7-4.5$ years), and thus any impacts from individual precipitation events or seasonal extremes are largely moderated. Overall, the SMBs have fairly high variability (coefficient of variation $=0.21)$. The mean $\mathrm{SMB}_{\delta 15 \mathrm{~N}}$ in the $20^{\text {th }}$ century $\left(126 \pm 26.5 \mathrm{~kg} \mathrm{~m}^{-2} \mathrm{a}^{-1}\right)$ is $34 \%$ greater than the mean $\mathrm{SMB}_{\delta 15 \mathrm{~N}}$ before $1900 \mathrm{CE}\left(94 \pm 18 \mathrm{~kg} \mathrm{~m}^{-2} \mathrm{a}^{-1}\right)$ and nearly $52 \%$ greater than the driest century that spans the $1600 \mathrm{~s}$ CE $\left(83 \pm 20 \mathrm{~kg} \mathrm{~m}^{-2} \mathrm{a}^{-1}\right)$ (Figure $\left.3 \mathrm{a}\right)$. 

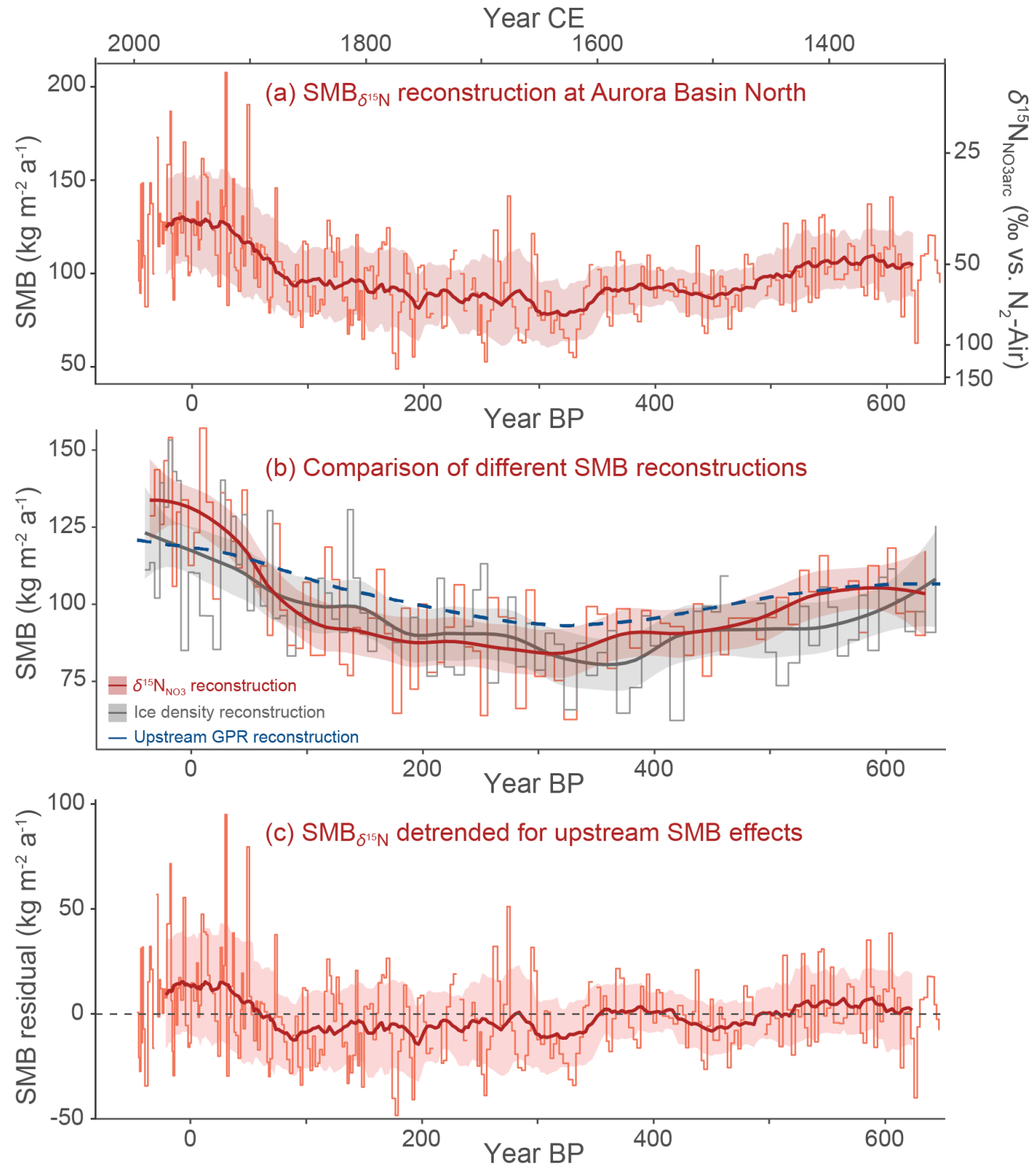

Figure 3. (a) Surface mass balance reconstruction for Aurora Basin North based on $\delta^{15} \mathrm{~N}_{\mathrm{NO} 3 \mathrm{arc}}$ data from the ABN1314-103 ice core. Reconstructed $\mathrm{SMB}_{\delta 15 \mathrm{~N}}$ values are shown by the red stepped lines with the 50 -yr running mean $\pm 1 \sigma$ overlaid as a darker thick line and shaded zone. (b) Comparison of SMBs reconstructed from $\delta^{15} \mathrm{~N}_{\mathrm{NO} 3}$ (red) with those from ice density (gray) and upstream GPR isochron depth ${ }^{39}$. The $\mathrm{SMB} \delta 15 \mathrm{~N}$ and $\mathrm{SMB}_{\mathrm{GPR}}$ values were aggregated to match the $1-\mathrm{m}$ resolution of the $\mathrm{SMB}_{\text {density }}$ data. For $\mathrm{SMB} \delta 15 \mathrm{~N}$ and $\mathrm{SMB}_{\text {density, }}$ smoothed LOESS curves are overlaid to more clearly show long-term patterns. (c) $\mathrm{SMB}_{\delta 15 \mathrm{~N}}$ values after the upstream topographic impact on SMBs has been removed, with 50 -yr running mean $\pm 1 \sigma$ values overlaid. The resulting residuals may better illustrate SMB variability due to climate change. 
We verified our new proxy's accuracy by comparing the $\mathrm{SMB}_{\delta 15 \mathrm{~N}}$ values with $\mathrm{SMBs}$ derived from the physical ice density ( $\mathrm{SMB}_{\text {density }}$ ) measurements of the same core. For each 1-m core

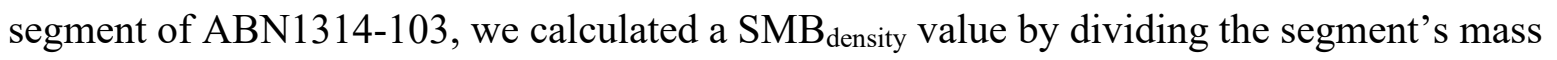
$(\mathrm{kg})$ by both its volume $\left(\mathrm{m}^{3}\right)$ and the age difference between the top and bottom of the segment $\left(\mathrm{a} \mathrm{m}^{-1}\right)$. The $\mathrm{SMB}_{\delta 15 \mathrm{~N}}$ (aggregated to match the $1-\mathrm{m}$ resolution) and SMB density share very similar mean values (100.8 vs. $98.0 \mathrm{~kg} \mathrm{~m}^{-2} \mathrm{a}^{-1}$, respectively) and total SMB ranges (62.0-157.3 vs. $61.7-153.4 \mathrm{~kg} \mathrm{~m}^{-2} \mathrm{a}^{-1}$, respectively), and the two SMB reconstructions have a similar pattern of variation with a moderate linear correlation $(r=+0.46, p<0.001, n=90)$ (Figure $3 b$ ). This agreement in mean value, range, and variability strongly validates our $\mathrm{SMB}_{\delta 15 \mathrm{~N}}$ approach and the potential of $\delta^{15} \mathrm{~N}_{\mathrm{NO} 3 a r c}$ as an accurate proxy for paleoenvironmental change.

Interpreting the ABN1314-103 SMB profile is more complicated than for ice cores drilled at dome summits because the ice sheet at the $\mathrm{ABN}$ drilling site is flowing at a rate of $16.2 \mathrm{~m} \mathrm{a}^{-1}$ 40. This means that the ice in ABN1314-103 actually fell as snow along a continuous $11.5 \mathrm{~km}$ transect upstream of the current $\mathrm{ABN}$ drilling site, with the oldest and deepest ice originating from the most distant upstream position. As a result, the $\delta^{15} \mathrm{~N}_{\mathrm{NO} 3 a r c}$ and core density have recorded any spatial SMB variability that existed along the upstream transect in addition to any SMB changes due to wetting or drying of the regional climate. Although overall elevation gain is small along the transect $(<15 \mathrm{~m})$, the region has abundant $0.5-1 \mathrm{~m}$ undulations in surface topography extending over horizontal extents of $3-10 \mathrm{~km}^{36}$. While the MAR's horizontal grid size $(35 \mathrm{~km})$ cannot resolve the SMB impact from these features, ground penetrating radar (GPR) performed along the upstream transect revealed that these 
surface slope changes correlate with SMB variations of up to $40 \mathrm{~kg} \mathrm{~m}^{-2} \mathrm{a}^{-1}$ as determined by isochronic internal reflection horizons ${ }^{39,41}$ (Figure 5). Although the long-term stability of such features is not well understood, the current surface features are still largely identifiable as buried horizons to depths below the deepest segment of ABN1314-103 with only steady horizontal offset due to ice flow.

By relating the upstream topographic-driven changes in SMB revealed by GPR to core depth through the horizontal ice flow rate and the core age-depth model ${ }^{39}$, we can determine the expected SMB signal due only to upstream surface topography ( $\left.\mathrm{SMB}_{\mathrm{GPR}}\right)$. We find that the general pattern of variability in $\mathrm{SMB}_{\mathrm{GPR}}$ correlates very well with the patterns recorded in the $\operatorname{SMB}_{\delta 15 \mathrm{~N}}(\mathrm{r}=+0.74)$ and $\mathrm{SMB}_{\text {density }}(\mathrm{r}=+0.63)$ records (Figure $\left.3 \mathrm{~b}\right)$. Thus, it appears that the primary SMB pattern preserved in ABN1314-103 is driven by upstream changes in surface slope, which is important for properly interpreting other environmental proxies contained in the ice and for understanding the local ice flow history.

\section{Discussion: Extracting a climate-driven SMB record}

To examine whether a secondary signal related to climate change was also preserved, we removed the spatial impact of upstream topography by subtracting the $\mathrm{SMB}_{\mathrm{GPR}}$ data from the $\operatorname{SMB}_{\delta 15 \mathrm{~N}}$ record. After this "upstream effect detrending" and accounting for the small offset in mean SMB values $\left(3.7 \mathrm{~kg} \mathrm{~m}^{-2} \mathrm{a}^{-1}\right)$, we find that the multi-decadal SMB values have been generally stable over the past 700 years (Figure 3c), with 50-yr running averages of the SMB never greater or less than $15 \mathrm{~kg} \mathrm{~m}^{-2} \mathrm{a}^{-1}$ from the detrended mean. These running averages suggest that drier conditions existed at $\mathrm{ABN}$ between 1600 and $1890 \mathrm{CE}$ (partially corresponding to the Little Ice Age) and that precipitation has increased in the most recent 100-150 years. This is generally consistent with what has been observed at other East 
Antarctic sites ${ }^{42-44}$ and for Antarctica as a whole ${ }^{11}$, but we recognize that this pattern is similar to the upstream topographic effect and that it might also arise if the $\mathrm{SMB}_{\mathrm{GPR}}$ record is excessively smoothed relative to true topographic-driven SMB variability (perhaps by the GPR data processing)

On shorter timescales, SMBs frequently change by $\approx 50 \mathrm{~kg} \mathrm{~m}^{-2} \mathrm{a}^{-1}$ around a common mean within 10-20 year periods. This pattern likely reflects the high interannual snowfall variability expected at sites like $\mathrm{ABN}^{13}$. Located at the transition between the coast and the interior East Antarctic Plateau, annual snow accumulation at $\mathrm{ABN}$ is sensitive to chance intrusions of extreme precipitation events and atmospheric rivers ${ }^{45,46}$, and the observed subdecadal $\mathrm{SMB}_{\delta 15 \mathrm{~N}}$ variability may represent the frequency of their stochastic occurrence at the site. Additionally, small scale surface roughness features like sastrugi may affect hyperlocal SMB (i.e., the SMB at scales of $<1 \mathrm{~m}$ ) through periods of enhanced accumulation and erosion as they migrate and evolve on the snow surface ${ }^{47-49}$. While the temporal evolution and possible life cycle cyclicity of surface roughness features are as yet poorly known, hyperlocal changes in SMB could also explain some of the short-term SMB variability observed in the $\mathrm{ABN}$ record if the sampling interval is shorter than the average duration of a surface feature at a given location.

\section{Discussion: Applied use and potential of the $\mathrm{SMB}_{\delta 15 \mathrm{~N}}$ proxy}

With over 8 million $\mathrm{km}^{2}$ of Antarctica having a SMB between 40 and $200 \mathrm{~kg} \mathrm{~m}^{-2} \mathrm{a}^{-1} 12$ and over $70 \%$ of the ice sheet area modeled to have $\delta^{15} \mathrm{~N}_{\mathrm{NO}}$ values markedly elevated by photolysis (Figure S6, Supplemental Text 4), the $\mathrm{SMB}_{\delta 15 \mathrm{~N}}$ proxy holds great potential for vastly expanding our knowledge of Antarctic SMB variability over time and space. 
than 200 years, with the East Antarctic Plateau particularly poorly represented ${ }^{11}$. For ice coring projects in these regions, the $\mathrm{SMB}_{\delta 15 \mathrm{~N}}$ proxy will excel at capturing the local effects of strong winds, irregular surface topography, and high interannual snowfall variability better than water isotopic techniques while avoiding problems with layer thinning and density modeling that affect $\mathrm{SMB}_{\text {density }}$ methods. As regional climate models still struggle to accurately simulate drifting snow and sublimation fluxes in the coast-to-plateau transition ${ }^{12}$, $\mathrm{SMB}_{\delta 15 \mathrm{~N}}$ can provide critical ground-based data for models predicting future contributions to sea level rise. The $\mathrm{SMB}_{\delta 15 \mathrm{~N}}$ proxy also holds particular value for helping constrain and validate models of upstream flow effects in research targeting ice streams and broad-scale 255 glacial flow patterns.

Additionally, sampling for the $\mathrm{SMB} \delta 15 \mathrm{~N}$ proxy can save valuable time and cost compared to existing alternatives in order to expand current records of modern SMBs. Obtaining new ground-based SMBs for sites without annually resolved layers requires either coring several meters to the increasingly buried Pinatubo volcanic horizon or repeated visits to newly 260 installed stake transects. However, limited time and resources for research expeditions to remote areas precludes intensive SMB surveys with these methods. With the $\mathrm{SMB}_{\delta 15 \mathrm{~N}}$ proxy, a mean site SMB could be determined with only a series of shallow snow or firn samples extending deep enough into the archived zone to cover only a few seasonal cycles (much shallower than the Pinatubo horizon). After proper mixing, only $\sim 0.3-1.0 \mathrm{~kg}$ would need to be kept, transported, and analyzed for each sample, which logistically allows for the rapid collection of robust SMB site means in many locations. On-site melting and $\mathrm{NO}_{3}{ }^{-}$ concentration could further reduce logistical requirements.

The $\mathrm{SMB}_{\delta 15 \mathrm{~N}}$ proxy promises to grow and adapt as studies on Antarctic $\mathrm{NO}_{3}{ }^{-}$dynamics continue. Because the resolution of $\delta^{15} \mathrm{~N}_{\mathrm{NO} \text { arc }}$ sampling is limited only by the minimum 
amount of $\mathrm{NO}_{3}{ }^{-}$needed for analysis, very finely-resolved $\delta^{15} \mathrm{~N}_{\mathrm{NO}}$ arc records can be obtained by increasing the mass of ice collected per depth unit (e.g., by specifically drilling whole cores or replicate cores for $\mathrm{NO}_{3}{ }^{-}$isotopes) and with advances in $\mathrm{NO}_{3}{ }^{-}$isotopic analysis expected in the near future ${ }^{50}$. This may allow for more precise multi-annual aggregations for $\mathrm{SMB}_{\delta 15 \mathrm{~N}}$ reconstructions and permit a deeper examination of subannual $\mathrm{NO}_{3}{ }^{-}$dynamics. Finally, SMBs from parts of the West Antarctic ice sheet and the highest elevations of the northern Greenland ice sheet fall within the appropriate range for the $\mathrm{SMB}_{\delta 15 \mathrm{~N}}$ proxy, and additional field sampling at those locations may allow us to reconstruct SMBs by verifying or adapting the relationship defined here for regional use outside of East Antarctica. Given the great potential of the $\mathrm{SMB} \delta 15 \mathrm{~N}$ proxy to advance our understanding of the Antarctic environment and its sensitivity to climate change, we strongly recommend that potential ice coring projects incorporate $\mathrm{NO}_{3}{ }^{-}$analyses into their planning and urge continued studies on Antarctic $\mathrm{NO}_{3}{ }^{-}$dynamics.

\section{Acknowledgements:}

285 We express thanks to the following individuals for project assistance and data support: Sarah Albertin, Selin Bagci, Albane Barbero, Mathieu Casado, Armelle Crouzet, Vincent Favier, Elsa Gautier, Gaspard Jannot, Alexis Lamothe, Anaïs Orsi, Fred Parrenin, Holly Winton, and the overwintering crews at Concordia Station. We acknowledge the logistical support of IPEV for the French missions in Antarctica, the IPEV and PNRA colleagues and overwintering crews at Concordia Station, and the JARE54 traverse team for fieldwork assistance and access to the S80 site data. We thank the co-investigators for the ABN drilling project (Jérome Chappellaz, Dorthe Dahl-Jensen, David Etheridge, Joe McConnell, Andrew Moy, Steven Phipps, Andrew Smith, Tessa Vance, Meredith Nation) and the French National 
Center for Coring and Drilling (C2FN, funded by INSU) for critical drilling, logistic, and analytical support at ABN and other sites. Finally, we acknowledge the Glacioclim-SAMBA, ITASE, and IPICS 2kyr Array programs for SMB data, the Air-O-Sol facility at IGE for microbial culturing, and additional support from the MITACS Globalink program and JSPSCNRS joint research program.

\section{Funding:}

SCADI: European Horizon Marie Skłodowska-Curie individual fellowship 889508

LabEx OSUG@2020 Investissements d'avenir: ANR10 LABX56

EAIIST: ANR-16-CE01-0011-01

BNP-Paribas Climate Initiative programs 1115 (CHICTABA), 1117 (CAPOXI 35-75), and 1169 (EAIIST)

CLIMCOR Equipex: ANR-11-EQPX-0009

MEXT/JSPS KAKENHI: 20H0496

\section{Author contributions:}

Conceptualization: PDA, JS, NC, MC

Investigation: All authors

$310 \quad$ Formal analysis: PDA, APMS, ELM

Visualization: PDA, ELM

Funding acquisition: PDA, JS, MC

Writing - original draft: PDA, APMS, PC

Writing - review \& editing: All authors

315 The authors declare that they have no competing interests

Data and materials availability: Data and code are available for reviewers at doi:10.5281/zenodo.5793694. Data have been submitted to PANGAEA and are in review for publishing.

\section{Methods}

Mathematical framework for $\delta^{15} N_{N O 3 a r c}$ and $S M B$ relationships

A linear relationship between $\delta^{15} \mathrm{~N}_{\mathrm{NO}}$ arc and the reciprocal of surface mass balance $\left(S M B^{-1}\right)$ has been previously observed and reported in Antarctica ${ }^{17,34,26}$. Here, we mathematically illustrate how this relationship between $\delta^{15} \mathrm{~N}_{\mathrm{NO} \text { arc }}$ and SMB arises through photolysis of 
$\mathrm{NO}_{3}^{-}$. We focus solely on the characteristics of $\mathrm{NO}_{3}{ }^{-}$contained within a given horizontal plane of snow that is located at the snowpack surface at $t=0$. We assume simplified sites with a stable surface mass balance $(S M B)$, clear sky conditions, no surface roughness, and no significant compaction with burial in the photic zone. Any $\mathrm{NO}_{3}{ }^{-}$that is photolyzed is immediately and permanently removed from the plane of snow, and $\mathrm{NO}_{3}{ }^{-}$recycling ${ }^{29,34}$ is assumed not to affect $\mathrm{NO}_{3}{ }^{-}$in the plane of snow during the burial process modeled here (i.e., after $t=0)$.

Defining the relationship between $\delta^{15} N_{N O 3 a r c}$ and $S M B$

The time that it takes for a given horizontal plane of snow to be buried from the surface to a particular depth $z$ is determined by the SMB $\left(\mathrm{kg} \mathrm{m}^{-2} \mathrm{a}^{-1}\right.$, converted to $\left.\mathrm{cm} \mathrm{s}^{-1}\right)$ :

$$
t_{(z)}=\frac{z}{S M B}
$$

The concentration of $\mathrm{NO}_{3}{ }^{-}$within a plane of snow decays through time according to:

$$
\frac{d[N O 3]}{d t}=-J_{(z)}[N O 3]_{(t)}
$$

where $J_{(z)}$ is the photolytic rate constant at a given depth defined as:

$$
J_{(z)}=\sigma \phi I_{(z)}
$$

where $\sigma$ is the absorption cross section for $\mathrm{NO}_{3}{ }^{-}$photolysis $\left(\mathrm{cm}^{2}\right), \phi$ is the quantum yield for $\mathrm{NO}_{3}{ }^{-}$photolysis $\left(\right.$molec photon ${ }^{-1}$ ), and $I_{(z)}$ is the actinic flux of ultraviolet irradiance (photon $\mathrm{cm}^{-2} \mathrm{~s}^{-1} \mathrm{~nm}^{-1}$ ) integrated over wavelengths that can induce photolysis of $\mathrm{NO}_{3}{ }^{-}$. However, this photolytic rate "constant" changes with depth because actinic flux exponentially decays with depth as:

$$
I_{(z)}=I_{0} e^{\frac{-z}{z_{e}}}
$$

where $I_{0}$ is the initial actinic flux that strikes the snow surface and $z_{e}$ is the $e$-folding depth (cm) of the snowpack. Note that non-exponential decay of $I$ in the top $\sim 2 \mathrm{~cm}$ of snowpack ${ }^{30}$ is simplified here by assuming the decay to be exponential from the snow surface. Equation (3) can then be expressed as:

$$
\frac{d[N O 3]}{d t}=-\sigma \phi I_{o} e^{\frac{-z}{z_{e}}}[N O 3]_{(t)}
$$

Through Eq. (2), we can rewrite Eq. (6) as: 


$$
\frac{d[N O 3]}{d t}=-\sigma \phi I_{o} e^{\frac{-S M B t}{z_{e}}}[N O 3]_{(t)}
$$

In order to determine the $\mathrm{NO}_{3}{ }^{-}$concentration at a given depth (i.e., $S M B \cdot t$ ), we derive:

$$
\frac{d[N O 3]}{[N O 3]_{(t)}}=-\sigma \phi I_{O} e^{\frac{-S M B t}{z_{e}}} d t
$$

And integrate to produce:

$$
\ln [N O 3]_{(t)}=\frac{\sigma \phi I_{O} z_{e} e^{\frac{-S M B t}{z_{e}}}}{S M B}+C
$$

Which simplifies to:

$$
[N O 3]_{(t)}=e^{c} e^{\frac{\sigma \phi I_{O} z_{e} e^{\frac{-S M B}{z_{e}}}}{S M B}}
$$

At $t=0,\left[\mathrm{NO}_{3}{ }^{-}\right]_{(\mathrm{t})}=\left[\mathrm{NO}_{3}{ }^{-}\right]_{0}$ and therefore:

$$
e^{c}=[N O 3]_{0} e^{\frac{-\sigma \phi I_{O} z_{e}}{S M B}}
$$

And thus combining Eq. (10) and Eq. (11):

$[N O 3]_{(t)}=[N O 3]_{0} e^{\frac{-\sigma \phi I_{O} z_{e}}{S M B}} e^{\frac{\sigma \phi I_{O} z_{e} e^{\frac{-S M B}{z_{e}}}}{S M B}}=[N O 3]_{0} e^{\frac{\sigma \phi I_{O} z_{e}\left(e^{\frac{-S M B}{z_{e}}}-1\right)}{S M B}}$

According to Eq. (12), as time (i.e., burial depth) increases, the $\mathrm{NO}_{3}{ }^{-}$concentration will decrease. However, the rate of decrease will lessen over time as the value of $S M B \cdot t$ approaches $3 z_{e}$, and below the photic zone (i.e., $z>3 z_{e}$ ) the $\mathrm{NO}_{3}{ }^{-}$concentration is largely stable and equal to $e^{c}$.

Therefore, we can calculate the fraction of $\mathrm{NO}_{3}{ }^{-}$archived below the photic zone $\left(f_{\text {NO3arc }}\right)$ as:

$$
f_{N O 3_{a r c}}=\frac{e^{c}}{[N O 3]_{0}}=\frac{[N O 3]_{0} e^{\frac{-\sigma \phi I_{o} z_{e}}{S M B}}}{[N O 3]_{0}}=e^{\frac{-\sigma \phi I_{O} z_{e}}{S M B}}
$$

To determine the $\delta^{15} \mathrm{~N}_{\mathrm{NO} 3}$ arc of this $\mathrm{NO}_{3}{ }^{-}$, Rayleigh fractionation states that $\delta^{15} \mathrm{~N}_{\mathrm{NO} 3}$ can be calculated with the fractionation factor $a$ by:

$$
\ln \left(\delta^{15} N_{N O 3_{a r c}}+1\right)=(\mathrm{a}-1) \ln \left(f_{N O 3_{a r c}}\right)+\ln \left(\delta^{15} N_{N O 3_{0}}+1\right)
$$

Through our prior calculation of $f_{N O 3 a r c}$ in Eq. (13), we thus produce:

$$
\ln \left(\delta^{15} N_{N O 3_{\text {arc }}}+1\right)=(\mathrm{a}-1) \frac{-\sigma \phi I_{O} z_{e}}{S M B}+\ln \left(\delta^{15} N_{N O 3_{0}}+1\right)
$$

Because $(\mathrm{a}-1)$ is negative for nitrogen during photolysis of $\mathrm{NO}_{3}{ }^{-21,22,31,51-53}$ and the other parameters are positive, this means that $\delta^{15} \mathrm{~N}_{\mathrm{NO}}$ arc will vary linearly and positively with $S M B^{-}$ ${ }^{1}$ when other parameters are held constant or scale linearly with $\mathrm{SMB}^{-1}$. We examine the 
potential impacts of variability in these other parameters more thoroughly in Supplementary Text 1.

Based on modeling and field observations, SMB is the primary driver of change in $\delta^{15} \mathrm{~N}_{\mathrm{NO}}$ arc values. Thus, the non-SMB variables can be subsumed into two parameters $A$ and $B$ to

410 function as linear regression coefficients, producing Eq. (1) of the main text:

$$
\ln \left(\delta^{15} N_{N O 3_{a r c}}+1\right)=\frac{A}{S M B}+B
$$

The inverse function of Eq. (1) can be used as a transfer function to calculate an SMB based on a $\delta^{15} \mathrm{~N}_{\mathrm{NO}}$ arc value:

$$
\frac{1}{S M B}=\frac{\ln \left(\delta^{15} N_{N O 3 a r c}+1\right)-B}{A}
$$

Finally, $\operatorname{since} \ln (\mathrm{x}+1) \approx \mathrm{x}$ when $\mathrm{x} \approx 0$, a simpler relationship of Eq. (15) can be approximated, in a form similar to that previously reported from field observations ${ }^{23,26,34}$ :

$$
\delta^{15} N_{N O 3_{a r c}}=(\mathrm{a}-1) \frac{-\sigma \phi I_{O} z_{e}}{S M B}+\delta^{15} N_{N O 3_{0}}
$$

\section{Snow sampling techniques}

The $\delta^{15} \mathrm{~N}_{\mathrm{NO} \text { arc }}$ values in our database are taken from a mix of previously reported values from Antarctic research traverses and values newly reported here (Figure 2). For all values, snow and ice containing $\mathrm{NO}_{3}{ }^{-}$was sampled in the field in one of three techniques: 1) 1-2 m deep snow pit with continuous sampling at regular intervals from top to bottom, 2) single sample taken of a well-mixed 5-10 cm layer around the 1-m depth layer, and 3) drilled core later cut at desired intervals. Since current $\mathrm{NO}_{3}{ }^{-}$isotopic analysis requires $50-150 \mathrm{nmol}$ of $\mathrm{NO}_{3}{ }^{-}, 0.25-1.50 \mathrm{~kg}$ of snow or ice per sample ${ }^{19,21}$ are gathered to ensure a sufficient amount of $\mathrm{NO}_{3}{ }^{-}$. Generally, the multiple samples produced by the snow pit technique offers the best and most flexible results, but the 1-m depth layer technique is valuable for quick sampling during limited stops, and cores are necessary to collect samples deeper than $\approx 5 \mathrm{~m}$.

\section{Laboratory analyses}

For $\delta^{15} \mathrm{~N}_{\mathrm{NO}}$ arc results included in our database that have been previously reported, readers are directed to the original papers for specific analytical and sampling techniques. For the 
$\delta^{15} \mathrm{~N}_{\mathrm{NO} 3 \text { arc }}$ data newly reported here, snow and ice samples were collected into clean sealed plastic bags or tubs and stored frozen until melted at room temperature for analysis. The $\mathrm{NO}_{3}{ }^{-}$ mass fraction $\left(\omega\left(\mathrm{NO}_{3}{ }^{-}\right)\right)$was determined on aliquots by either a colorimetric method or ion chromatography with detection limits $<0.5 \mathrm{ng} \mathrm{g}^{-1}$ and precision of $<3 \%{ }^{21,22}$. The remaining melted samples were passed through an anionic exchange resin (Bio-Rad ${ }^{\mathrm{TM}} \mathrm{AG} 1-\mathrm{X} 8$, chloride form), and the resulting trapped $\mathrm{NO}_{3}{ }^{-}$was eluted with $10 \mathrm{ml}$ of $\mathrm{NaCl} 1 \mathrm{M}$ solution. Isotopic analysis occurred at IGE-CNRS, Grenoble, France, where $\mathrm{NO}_{3}{ }^{-}$in these samples was converted to $\mathrm{N}_{2} \mathrm{O}$ with the denitrifying bacteria Pseudomonas aureofaciens (lacking nitrous oxide reductase), thermally decomposed into $\mathrm{O}_{2}$ and $\mathrm{N}_{2}$ on a $900^{\circ} \mathrm{C}$ gold surface, and separated by gas chromatography with a GasBench IITM. Oxygen and nitrogen isotopic ratios were then measured on a Thermo Finnigan ${ }^{\mathrm{TM}}$ MAT 253 mass spectrometer ${ }^{54-57}$. Isotopic effects from this analysis were corrected as described by Morin et al. (2009) and Frey at al. (2009), using the international reference materials USGS 32, USGS 34, and USGS 35 with ultrapure Dome C water used for standards and samples throughout the analyses to account for potential oxygen isotopic exchanges. Results are reported relative to Vienna Standard Mean Ocean Water (V-SMOW) for oxygen isotopes ${ }^{58}$ and $\mathrm{N}_{2}$-Air for nitrogen isotopes ${ }^{59}$. For snow pits with multiple sequential $\delta^{15} \mathrm{~N}_{\mathrm{NO} 3 \text { arc }}$ values, a single $\delta^{15} \mathrm{~N}_{\mathrm{NO} 3 \text { arc }}$ value was calculated as the aggregate of samples $30+\mathrm{cm}$ deep, weighted by the relative mass $\mathrm{of}_{3}{ }^{-}$ per sample. Although the photic zone boundary can extend lower than $30 \mathrm{~cm}$ at some sites ${ }^{29,30}$, this cutoff was deemed an acceptable compromise to include more data from pits that stopped at $50 \mathrm{~cm}$ depth as the great majority of photolysis will have occurred within the top $30 \mathrm{~cm}$ due to exponential decay of actinic flux and $\omega\left(\mathrm{NO}_{3}{ }^{-}\right)$with depth. Exceptions to this were made for three coastal pits from Cap Prud'homme (weighted-means of $3+\mathrm{cm}$ samples), where high accumulation greatly reduces photolytic impact, higher snow impurities reduce the photic zone depth, and a broader aggregation is necessary to smooth seasonal cycles. 
Additionally, two pits from Dronning Maud Land were aggregated with $15+\mathrm{cm}$ samples based on shallow $3 z_{e}$ values $(2-5 \mathrm{~cm})$ calculated on site during snow pit sampling ${ }^{29}$. For cores included in our database, a single $\delta^{15} \mathrm{~N}_{\text {NO3arc }}$ value was calculated as the isotopic mean of samples extending from present back to no earlier than $1800 \mathrm{CE}$.

Noro et al. (2018) reported $\delta^{15} \mathrm{~N}_{\mathrm{NO}}$ values for 16 pits along the JARE54 and JARE57 transects, but the sampling methodology for these pits took a single well-mixed sample of the entire pit depth which included the entire photic zone. In order to estimate the $\delta^{15} \mathrm{~N}_{\mathrm{NO}}$ arc values of these sites (i.e., the value as if the photic zone snow had been excluded), we applied a correction factor calculated using data from other pits in our database that were taken on two similar transects spanning from the coast to other interior domes (Dome A and Dome C) of East Antarctica ${ }^{22,23}$. Because each of the pits on the Dome A and Dome C transects were continuously sampled at discrete intervals from the surface to a point below the photic zone, we calculated different weighted-mean $\delta^{15} \mathrm{~N}_{\mathrm{NO} 3}$ values for selected depth spans that matched the three extents of the JARE pits: $0-30 \mathrm{~cm}, 0-50 \mathrm{~cm}$, and 0-80 cm. Corrective factors were calculated through the linear regression of $\delta^{15} \mathrm{~N}_{\mathrm{NO} 3 \text { arc }}$ vs. $\delta^{15} \mathrm{~N}_{\mathrm{NO}}$.X from Dome A/Dome C transect pits (where $\delta^{15} \mathrm{~N}_{\mathrm{NO} 3 a r c}$ is our database's $\delta^{15} \mathrm{~N}_{\mathrm{NO} 3}$ value from the archived zone and $\delta^{15} \mathrm{~N}_{\mathrm{NO3.X}}$ is the weighted-mean value of samples from the surface to depth $x: 30,50$, or 80 $\mathrm{cm}$ ) and applied to the JARE pit data through the appropriate depth correction (Table 1,2). Corrections were not made for JARE samples where $\delta^{15} \mathrm{~N}_{\mathrm{NO} 3}<0 \%$, as these low $\delta^{15} \mathrm{~N}_{\mathrm{NO} 3}$ values strongly suggest that photolysis was not a significant factor at these coastal sites, and photic zone corrections were thus not warranted.

Table 1. Linear regressions of $\delta^{15} \mathrm{~N}_{\mathrm{NO} 3 \text { arc }}$ vs. $\delta^{15} \mathrm{~N}_{\mathrm{NO} 3 . \mathrm{X}}$ (where $\mathrm{X}$ is 30,50 , or $80 \mathrm{~cm}$ ) calculated from nonJARE pit data in the $\delta^{15} \mathrm{~N}_{\mathrm{NO} 3}$ database.

\begin{tabular}{|c|c|c|c|}
\hline $\begin{array}{c}\text { Depth } \\
\text { correction }\end{array}$ & $\begin{array}{c}\text { Slope } \\
\text { (\%o/ /\%) }\end{array}$ & $\begin{array}{c}\text { Intercept } \\
\text { (\%) }\end{array}$ & $\mathbf{r}^{\mathbf{2}}$ \\
\hline $0-30 \mathrm{~cm}$ & $1.9 \pm 0.1$ & $-2.4 \pm 11.3$ & 0.89 \\
\hline $0-50 \mathrm{~cm}$ & $1.6 \pm 0.1$ & $-1.7 \pm 8.2$ & 0.94 \\
\hline $0-80 \mathrm{~cm}$ & $1.5 \pm 0.1$ & $-0.9 \pm 7.8$ & 0.94 \\
\hline
\end{tabular}


Table 2 . The $\delta^{15} \mathrm{~N}_{\mathrm{NO} 3}$ values for JARE sites included in our database as originally reported by Noro et al. (2018) and the $\delta^{15} \mathrm{~N}_{\mathrm{NO} 3 \mathrm{arc}}$ values corrected here to account for photic zone snow included in the original samples. Samples with original $\delta^{15} \mathrm{~N}_{\mathrm{NO} 3}$ values $<0 \%$ (italicized) were not corrected.

\begin{tabular}{|l|r|r|r|}
\hline JARE site & $\begin{array}{c}\text { Depth } \\
(\mathbf{c m})\end{array}$ & \multicolumn{1}{|c|}{$\begin{array}{c}\text { Original } \\
\boldsymbol{\delta}^{\mathbf{1 5}} \mathbf{N}_{\mathbf{N O 3}} \mathbf{( \% )}\end{array}$} & $\begin{array}{c}\text { Corrected } \\
\boldsymbol{\delta}^{\mathbf{5} \mathbf{N}_{\mathbf{N O 3 a r c}}} \mathbf{( \% )}\end{array}$ \\
\hline Z2 & $0-80$ & 20.6 & 30.8 \\
\hline IM0 & $0-50$ & 25.7 & 40.3 \\
\hline NMD304 & $0-50$ & 41.1 & 65.4 \\
\hline MD590 & $0-50$ & 83.5 & 134.7 \\
\hline DF1 & $0-30$ & 127.3 & 236.5 \\
\hline NDF & $0-30$ & 111.7 & 207.2 \\
\hline Plateau S & $0-30$ & 165.5 & 308.1 \\
\hline S80 & $0-30$ & 90.7 & 167.8 \\
\hline Fuji Pass & $0-30$ & 74.3 & 137.0 \\
\hline DF2 & $0-30$ & 118.6 & 220.1 \\
\hline S30 & $0-50$ & -19.0 & -19.0 \\
\hline H42 & $0-50$ & -6.6 & -6.6 \\
\hline H68 & $0-50$ & -14.5 & -14.5 \\
\hline H88 & $0-50$ & -19.4 & -19.4 \\
\hline H108 & $0-50$ & -6.4 & -6.4 \\
\hline H128 & $0-50$ & 14.1 & 21.3 \\
\hline
\end{tabular}

\section{SMB data}

In our database, $74 \delta^{15} \mathrm{~N}_{\mathrm{NO}}$ arc samples are represented by 51 unique direct ground measurements of SMB ( $\left.\mathrm{SMB}_{\text {ground }}\right)$ values observed at or near the $\mathrm{NO}_{3}{ }^{-}$sampling site, with the numerical discrepancy due to some sites having replicate $\delta^{15} \mathrm{~N}_{\mathrm{NO} 3 \mathrm{arc}}$ samples. These previously reported $\mathrm{SMB}_{\text {ground }}$ values were determined by measuring the change in surface height on established stakes or poles, by measuring the mass between known volcanic or radioactivity horizons in an ice core, or by ground penetrating radar (GPR) identification of dated horizons ${ }^{10,22,23,60-67}$.

Regional climate models can be used to estimate modern SMB rates for sites lacking ground observations $^{7,12}$, and we used the Modèle Atmosphérique Régional (MAR) version 3.6.4 with European Centre for Medium-Range Weather Forecasts "Interim" re-analysis data (ERAinterim) data as applied by Agosta et al. (2019) to model mean annual SMBs at all database sites for the period 1979-2017 $7^{12}$. Because the MAR overestimates SMBs at higher and more interior sites of the East Antarctic plateau ${ }^{68}$, we calculated a correction factor through linear 
regressions of $\mathrm{SMB}_{\text {ground }}$ Vs. MAR-estimated SMBs ( $\left.\mathrm{SMB}_{\mathrm{MAR}}\right)$ for our 51 sites that have both

values (Table 3, Figure 4). This correction was applied to all original MAR estimates to

produce "adjusted-MAR” SMBs (SMBadjMAR) that match more closely with ground

observations.

510 Table 3. A list of all sampling sites that have a $\mathrm{SMB}_{\text {ground }}$ observation with corresponding values of original $\mathrm{SMB}_{\mathrm{MAR}}$ and $\mathrm{SMB}_{\text {adjMAR }}$ (Figure 4). The difference between the $\mathrm{SMB}_{\text {adjMAR }}$ and $\mathrm{SMB}_{\mathrm{MAR}}$ values is given in the final column.

\begin{tabular}{|c|c|c|c|c|c|}
\hline Site & $\begin{array}{l}\text { SMB } \text { ground } \\
\left(\mathrm{kg} \mathrm{m}^{-2} \mathrm{a}^{-1}\right)\end{array}$ & $\begin{array}{c}\mathrm{SMB}_{\mathrm{MAR}} \\
\left(\mathrm{kg} \mathrm{m}^{-2} \mathrm{a}^{-1}\right)\end{array}$ & $\begin{array}{l}\text { SMB }_{\text {adjMAR }} \\
\left(\mathrm{kg} \mathrm{m}^{-2} \mathrm{a}^{-1}\right)\end{array}$ & $\begin{array}{c}\text { SMB }_{\text {adjMAR }}-\text { SMB }_{\text {MAR }} \\
\left(\mathrm{kg} \mathrm{m}^{-2} \mathbf{a}^{-1}\right)\end{array}$ & $\begin{array}{c}\text { SMB }_{\text {adjMAR }} / \\
\text { SMB }_{\text {MAR }}\end{array}$ \\
\hline Vostok & 22.6 & 30.4 & 24.1 & -6.3 & 0.79 \\
\hline DomeA & 22.9 & 40.9 & 34.4 & -6.5 & 0.84 \\
\hline ZtoA-P6 & 25.4 & 62.1 & 55.2 & -6.9 & 0.89 \\
\hline DomeC & 28.4 & 41.0 & 34.5 & -6.5 & 0.84 \\
\hline DomeF & 29.2 & 35.6 & 29.2 & -6.4 & 0.82 \\
\hline NDF & 30.9 & 33.2 & 26.8 & -6.4 & 0.81 \\
\hline Plateau S & 32.4 & 31.2 & 24.8 & -6.4 & 0.79 \\
\hline ZtoA-P5 & 33.3 & 61.5 & 54.6 & -6.9 & 0.89 \\
\hline preeaiist.18 & 34.0 & 47.8 & 41.1 & -6.7 & 0.86 \\
\hline S80Jare & 37.5 & 31.3 & 24.9 & -6.4 & 0.80 \\
\hline MD590 & 37.9 & 42.6 & 36.0 & -6.6 & 0.85 \\
\hline Fuji Pass & 40.7 & 35.0 & 28.6 & -6.4 & 0.82 \\
\hline ZtoA-P4 & 54.8 & 55.4 & 48.6 & -6.8 & 0.88 \\
\hline NMD304 & 65.8 & 75.6 & 68.4 & -7.2 & 0.90 \\
\hline IM0 & 68.5 & 99.2 & 91.6 & -7.6 & 0.92 \\
\hline Kohnen & 75.0 & 97.6 & 90.0 & -7.6 & 0.92 \\
\hline posteaiist.asuma05 & 76.0 & 288.9 & 266.9 & -22.0 & 0.92 \\
\hline preeaiist. 15 & 80.0 & 70.0 & 62.9 & -7.1 & 0.90 \\
\hline preeaiist.13 & 86.0 & 95.1 & 87.5 & -7.6 & 0.92 \\
\hline ZtoA-P3 & 90.7 & 76.3 & 69.1 & -7.2 & 0.91 \\
\hline CPH.D5 & 97.6 & 139.7 & 124.8 & -8.3 & 0.89 \\
\hline ZtoA-P2 & 99.4 & 95.6 & 88.0 & -7.6 & 0.92 \\
\hline $\mathrm{Z} 2$ & 113.5 & 116.9 & 108.9 & -8.0 & 0.93 \\
\hline posteaiist.stop36 & 118.0 & 147.5 & 138.3 & -9.2 & 0.94 \\
\hline CPH.D24 & 120.0 & 247.2 & 228.9 & -18.3 & 0.93 \\
\hline preeaiist.12 & 130.0 & 113.3 & 105.4 & -7.9 & 0.93 \\
\hline $\mathrm{ABN}$ & 130.0 & 122.0 & 113.9 & -8.1 & 0.93 \\
\hline posteaiist.asuma06 & 131.0 & 280.4 & 259.1 & -21.3 & 0.92 \\
\hline $\mathrm{H} 128$ & 158.8 & 210.2 & 195.3 & -14.9 & 0.93 \\
\hline preeaiist.06 & 160.0 & 286.2 & 264.4 & -21.8 & 0.92 \\
\hline preeaiist.07 & 171.0 & 269.5 & 249.2 & -20.3 & 0.92 \\
\hline ZtoA-P1 & 172.0 & 153.4 & 143.7 & -9.7 & 0.94 \\
\hline $\mathrm{H} 108$ & 185.0 & 250.7 & 232.1 & -18.6 & 0.93 \\
\hline preeaiist.09 & 198.0 & 201.0 & 186.9 & -14.1 & 0.93 \\
\hline H88 & 207.3 & 245.5 & 227.4 & -18.1 & 0.93 \\
\hline posteaiist.asuma04 & 215.0 & 304.2 & 280.8 & -23.4 & 0.92 \\
\hline posteaiist.asuma09 & 219.0 & 256.6 & 237.5 & -19.1 & 0.93 \\
\hline H68 & 225.4 & 255.7 & 236.7 & -19.0 & 0.93 \\
\hline $\mathrm{H} 42$ & 234.9 & 272.5 & 251.9 & -20.6 & 0.92 \\
\hline posteaiist.asuma02 & 239.0 & 343.0 & 316.0 & -27.0 & 0.92 \\
\hline posteaiist.asuma10 & 240.0 & 232.0 & 215.1 & -16.9 & 0.93 \\
\hline
\end{tabular}




\begin{tabular}{|l|r|r|r|r|r|}
\hline posteaiist.asuma11 & 243.0 & 203.6 & 189.3 & -14.3 & 0.93 \\
\hline S30-JARE & 271.9 & 288.6 & 266.6 & -22.0 & 0.92 \\
\hline posteaiist.asuma07 & 273.0 & 271.1 & 250.7 & -20.4 & 0.92 \\
\hline preeaiist.04 & 280.0 & 330.1 & 304.3 & -25.8 & 0.92 \\
\hline posteaiist.asuma01 & 321.0 & 337.4 & 310.9 & -26.5 & 0.92 \\
\hline preeaiist.03 & 337.7 & 366.0 & 337.0 & -29.0 & 0.92 \\
\hline cph.d17 & 446.0 & 178.1 & 166.1 & -12.0 & 0.93 \\
\hline preeaiist.02 & 487.8 & 439.0 & 403.3 & -35.7 & 0.92 \\
\hline asuma.2016.2 & 488.0 & 312.5 & 288.3 & -24.2 & 0.92 \\
\hline asuma.2016.1 & 548.0 & 366.5 & 337.4 & -29.1 & 0.92 \\
\hline
\end{tabular}

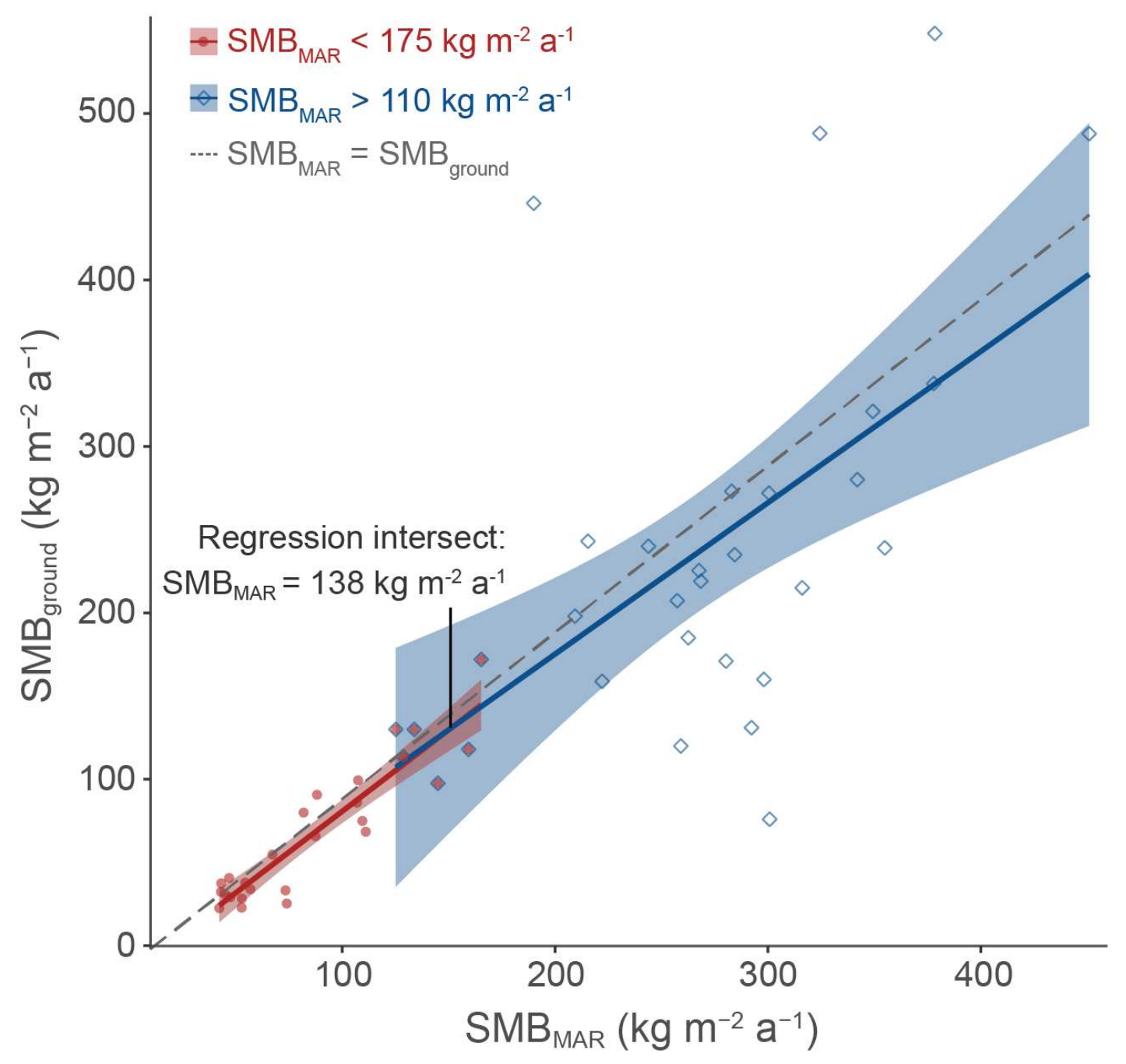

515 Figure 4. Linear regressions of $\mathrm{SMB}_{\text {ground }}$ versus $\mathrm{SMB}_{\mathrm{MAR}}$ for the period 1979-2017 at the 51 sites with $\mathrm{SMB}_{\text {ground }}$ observations, with $95 \%$ confidence intervals of the regressions shaded. Sites are subset for two overlapping regressions that intersect at $(138,130)$. These linear regressions were applied to the $\mathrm{SMB}_{\mathrm{MAR}}$ values for all sampling sites to produce the $\mathrm{SMB}_{\mathrm{adjMAR}}$ used in analyses. The dashed line represents a slope of 1 (i.e., if the $\mathrm{SMB}_{\mathrm{MAR}}$ perfectly matched the $\mathrm{SMB}_{\text {ground }}$ ).

A linear regression was calculated for two overlapping subsets of sites: one for the set of well-grouped sites where the $\mathrm{SMB}_{\mathrm{MAR}}$ is $<175 \mathrm{~kg} \mathrm{~m}^{-2} \mathrm{a}^{-1}$ and another for all sites where $\mathrm{SMB}_{\mathrm{MAR}}$ is $>110 \mathrm{~kg} \mathrm{~m}^{-2} \mathrm{a}^{-1}$. This first regression is tightly constrained $\left(\mathrm{SMB}_{\text {ground }}=1.0 \pm\right.$ 
$\left.0.1 \times \mathrm{SMB}_{\mathrm{MAR}}-5.8 \pm 7.1, \mathrm{r}^{2}=0.84\right)$, and it performs well to better align the $\mathrm{SMB}_{\mathrm{MAR}}$ estimates with the $\mathrm{SMB}_{\text {ground }}$ values at low SMB sites. The second regression covers samples with where some differences between $\mathrm{SMB}_{\mathrm{MAR}}$ and $\mathrm{SMB}_{\text {ground }}$ are very large, particularly at lower elevation sites where intense aeolian erosion and deposition can produce highly variable local SMB rates that are difficult to accurately model ${ }^{12,13}$. As a result, this regression is weaker $\left(\mathrm{SMB}_{\text {ground }}=0.9 \pm 0.2 \times \mathrm{SMB}_{\mathrm{MAR}}+4.2 \pm 57.9, \mathrm{r}^{2}=0.35\right)$ than the first regression, but we apply it while acknowledging the possibility of wide deviations. The two regressions intersect at $\left(\mathrm{SMB}_{\mathrm{MAR}}=138 \mathrm{~kg} \mathrm{~m}^{-2} \mathrm{a}^{-1}, \mathrm{SMB}_{\text {ground }}=130 \mathrm{~kg} \mathrm{~m}^{-2} \mathrm{a}^{-1}\right)$, and thus $\mathrm{SMB}_{\text {adjMAR }}$ values were calculated by applying the first regression to all sites where $\mathrm{SMB}_{\mathrm{MAR}} \leq 138 \mathrm{~kg}$ $\mathrm{m}^{-2} \mathrm{a}^{-1}$ and applying the second regression to all sites where $\mathrm{SMB}_{\mathrm{MAR}}>138 \mathrm{~kg} \mathrm{~m}^{-2} \mathrm{a}^{-1}$. We constructed our final primary SMB dataset for the analysis of $\delta^{15} \mathrm{~N}_{\mathrm{NO} 3 \text { arc }}$ samples by using the best quality SMB data for each site: $\mathrm{SMB}_{\text {ground }}$ if available and $\mathrm{SMB}_{\text {adjMAR }}$ otherwise.

\section{Transfer function and SMB reconstruction}

We modeled linear relationships between $\ln \left(\delta^{15} \mathrm{~N}_{\mathrm{NO}}+1\right)$ and $\mathrm{SMB}^{-1}$ based on Eq. (15) using previously reported parameter values to compare our theoretical framework to field results and to better understand the sensitivity of the relationships to photolytic and fractionation factors (Supplementary Text 1). To determine the coefficients in Eq. (1) from our field data, we performed linear regressions using all database samples and the primary SMB dataset. Additional regressions (Supplementary Text 2) were performed for subsets of the database based on SMB type $\left(\mathrm{SMB}_{\text {ground }} \mathrm{Vs}\right.$. $\left.\mathrm{SMB}_{\text {adjMAR }}\right)$. With regression coefficients determined for Eq. (1), we modeled the spatial distribution of $\delta^{15} \mathrm{~N}_{\mathrm{NO}}$ arc values across Antarctica using gridded mean SMBs (MAR-ERA-interim, 1979-2015) at a $35 \mathrm{~km}$ resolution ${ }^{12}$ that were converted to $\mathrm{SMB}_{\text {adjMAR }}$ as previously described. 
For reconstructing the $\mathrm{ABN} \mathrm{SMB}_{\delta 15 \mathrm{~N}}$ history, the $\mathrm{ABN} 1314-103$ ice core was cut into $0.33 \mathrm{~m}$ samples from 5 to $103 \mathrm{~m}$, and these were processed for $\mathrm{NO}_{3}{ }^{-}$isotopes in 2016 as previously described. We applied an annually-resolved age model (ALC01112018) based on seasonal ion and water isotope cycles and constrained by volcanic horizons that was originally developed for a longer core also taken at $\mathrm{ABN}$. Each $1 \mathrm{~m}$ ice core segment was individually weighed prior to cutting, and the mass and volume were used to calculate a SMB profile based on dated ice density changes (SMB density $_{\text {. }}$.

To determine past topographical effects on SMBs, a MALA GPR device towing a RTA antenna on the surface (50 MHz out, $100 \mathrm{MHz}$ in) was operated for a $65 \mathrm{~km}$ transect upstream of the coring site as part of the 2013-2014 campaign. Radar was triggered every 2 seconds (i.e., every 6-7 $\mathrm{m}$ along the transect) with a recording time window of 3000 nanoseconds that captured returns down to $300 \mathrm{~m}$ depth. After postprocessing ${ }^{41}$, isochronic internal reflecting horizons were identified to $220 \mathrm{~m}$ depth, digitized with ReflexW software, and dated by connecting to the ALC01112018 age-depth model. Using a density profile taken from a longer ice core simultaneously drilled at $\mathrm{ABN}, 2 \mathrm{D}$ fields (depth by transect distance) were calculated for age, mean accumulation rate, and local accumulation rate. The mean accumulation rate to the most shallow reflecting horizon was taken as the upstream topographical effect on SMBs (i.e., $\mathrm{SMB}_{\mathrm{GPR}}$ ).

Statistical analyses, regressions, SMB reconstructions, visualizations, and other statistical analyses were perform using the R programming language with packages ggplot2, RColorBrewer, gridExtra, cowplot, and tidyverse. 


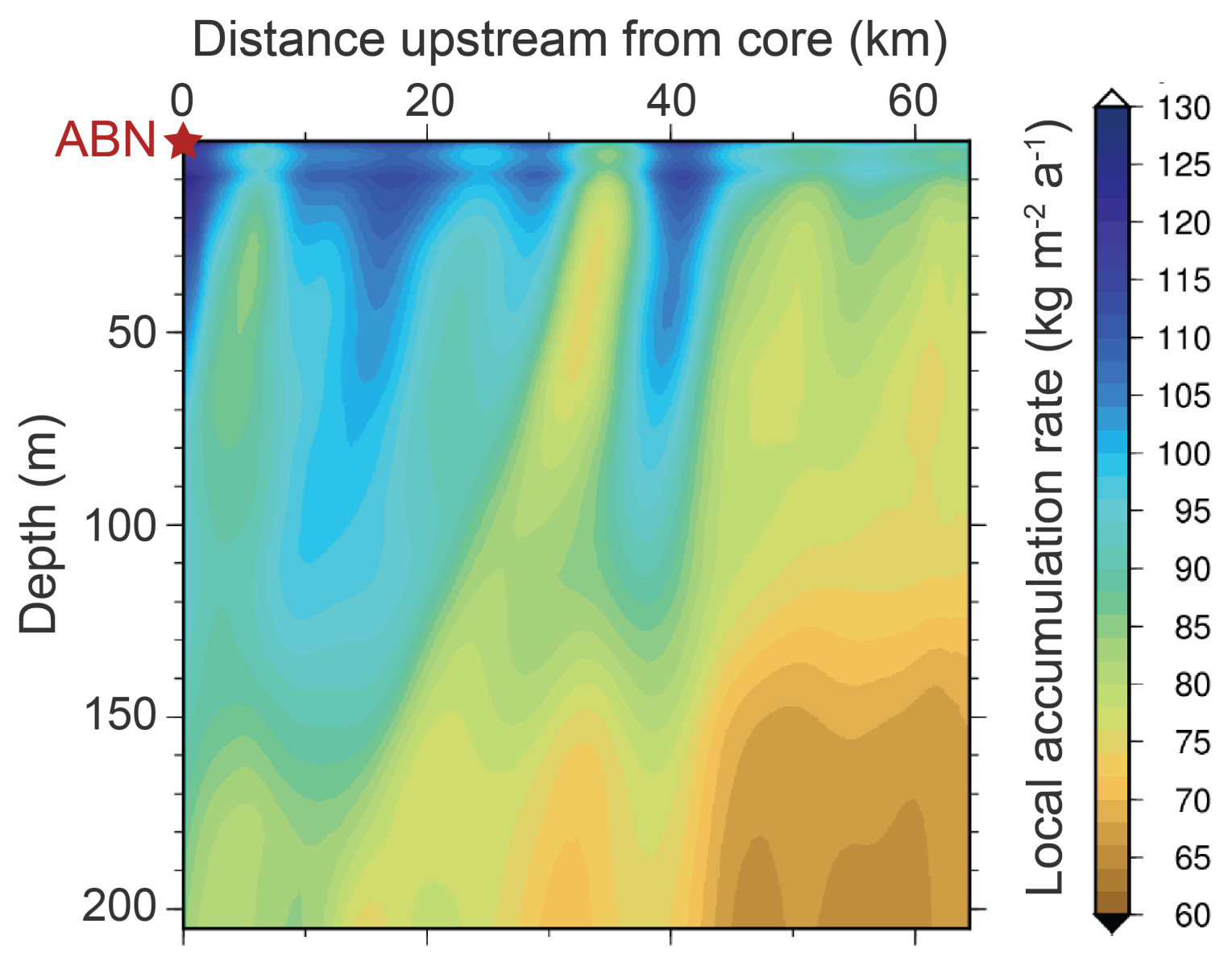

570 Figure 5. Local accumulation rate variability with depth along the upstream ABN transect determined from GPR identification of isochronic internal reflective horizons. Accumulation rates have an original depth resolution of $0.5 \mathrm{~m}$ which is smoothed through a moving age-depth average with a cosine weighting window to reduce isochron artifacts ${ }^{41}$. 
1. Fretwell, P. et al. Bedmap2: improved ice bed, surface and thickness datasets for Antarctica. The Cryosphere 7, 375-393 (2013).

2. Juckes, M. N., James, I. N. \& Blackburn, M. The influence of Antarctica on the momentum budget of the southern extratropics. Quarterly Journal of the Royal Meteorological Society 120, 1017-1044 (1994).

3. M.R. van den Broeke. On the role of Antarctica as heat sink for the global atmosphere. J. Phys. IV France 121, 115-124 (2004).

4. Bronselaer, B. et al. Change in future climate due to Antarctic meltwater. Nature 564, 53-58 (2018).

5. Starr, A. et al. Antarctic icebergs reorganize ocean circulation during Pleistocene glacials. Nature 589, 236-241 (2021).

6. IPCC. Climate Change 2014: Synthesis Report. Contribution of Working Groups I, II and III to the Fifth Assessment Report of the Intergovernmental Panel on Climate Change [Core Writing Team, R.K. Pachauri and L.A. Meyer (eds.)]. 151 (2014).

7. Shepherd, A. et al. Mass balance of the Antarctic Ice Sheet from 1992 to 2017. Nature 558, 219-222 (2018).

8. Martín-Español, A. et al. Spatial and temporal Antarctic Ice Sheet mass trends, glacio-isostatic adjustment, and surface processes from a joint inversion of satellite altimeter, gravity, and GPS data. Journal of Geophysical Research: Earth Surface 121, 182-200 (2016).

9. Stauffer, B., Flückiger, J., Wolff, E. \& Barnes, P. The EPICA deep ice cores: first results and perspectives. Annals of Glaciology 39, 93-100 (2004).

10. Parrenin, F. et al. 1-D-ice flow modelling at EPICA Dome C and Dome Fuji, East Antarctica. Clim. Past 3, 243-259 (2007).

11. Thomas, E. R. et al. Regional Antarctic snow accumulation over the past 1000 years. Clim. Past 13, 14911513 (2017).

12. Agosta, C. et al. Estimation of the Antarctic surface mass balance using the regional climate model MAR (1979-2015) and identification of dominant processes. The Cryosphere 13, 281-296 (2019).

13. Agosta, C. et al. A 40-year accumulation dataset for Adelie Land, Antarctica and its application for model validation. Climate Dynamics 38, 75-86 (2012).

14. Gallée, H. et al. Transport of Snow by the Wind: A Comparison Between Observations in Adélie Land, Antarctica, and Simulations Made with the Regional Climate Model MAR. Boundary-Layer Meteorology 146, 133-147 (2013). 
15. Vimeux, F., Cuffey, K. M. \& Jouzel, J. New insights into Southern Hemisphere temperature changes from Vostok ice cores using deuterium excess correction. Earth and Planetary Science Letters 203, 829-843 (2002).

16. Cauquoin, A. et al. Comparing past accumulation rate reconstructions in East Antarctic ice cores using 10Be, water isotopes and CMIP5-PMIP3 models. Clim. Past 11, 355-367 (2015).

17. Freyer, H. D., Kobel, K., Delmas, R. J., Kley, D. \& Legrand, M. R. First results of 15N/14N ratios in nitrate from alpine and polar ice cores. Tellus B 48, 93-105 (1996).

18. Legrand, M., Wolff, E., Wagenbach, D. \& Jacka, T. Antarctic aerosol and snowfall chemistry: implications for deep Antarctic ice-core chemistry. Annals of Glaciology, Vol 29, 1999 29, 66-72 (1999).

19. Wolff, E. Nitrate in Polar Ice. in Ice Core Studies of Global Biogeochemical Cycles (Springer-Verlag, 1995).

20. Röthlisberger, R. et al. Nitrate in Greenland and Antarctic ice cores: a detailed description of postdepositional processes. Annals of Glaciology 35, 209-216 (2002).

21. Frey, M., Savarino, J., Morin, S., Erbland, J. \& Martins, J. Photolysis imprint in the nitrate stable isotope signal in snow and atmosphere of East Antarctica and implications for reactive nitrogen cycling. Atmospheric Chemistry and Physics 9, 8681-8696 (2009).

22. Erbland, J. et al. Air-snow transfer of nitrate on the East Antarctic Plateau - Part 1: Isotopic evidence for a photolytically driven dynamic equilibrium in summer. Atmospheric Chemistry and Physics 13, 6403-6419 (2013).

23. Shi, G. et al. Investigation of post-depositional processing of nitrate in East Antarctic snow: isotopic constraints on photolytic loss, re-oxidation, and source inputs. Atmospheric Chemistry and Physics 15, 9435-9453 (2015).

24. Grannas, A. et al. An overview of snow photochemistry: evidence, mechanisms and impacts. Atmospheric Chemistry and Physics 7, 4329-4373 (2007).

25. Berhanu, T. et al. Laboratory study of nitrate photolysis in Antarctic snow. II. Isotopic effects and wavelength dependence. Journal of Chemical Physics 140, (2014).

26. Noro, K. et al. Spatial variation of isotopic compositions of snowpack nitrate related to post-depositional processes in eastern Dronning Maud Land, East Antarctica. Geochemical Journal 52, e7-e14 (2018).

27. Shi, G. et al. Isotope fractionation of nitrate during volatilization in snow: A field investigation in Antarctica. Geophysical Research Letters 46, 3287-3297 (2019). 
28. Noro, K. \& Takenaka, N. Post-depositional loss of nitrate and chloride in Antarctic snow by photolysis and sublimation: a field investigation. POLAR 39, (2020).

29. Winton, V. H. L. et al. Deposition, recycling, and archival of nitrate stable isotopes between the air-snow interface: comparison between Dronning Maud Land and Dome C, Antarctica. Atmos. Chem. Phys. 20, 5861-5885 (2020).

30. Zatko, M. C. et al. The influence of snow grain size and impurities on the vertical profiles of actinic flux and associated NOx emissions on the Antarctic and Greenland ice sheets. Atmos. Chem. Phys. 13, 35473567 (2013).

31. Zatko, M., Geng, L., Alexander, B., Sofen, E. \& Klein, K. The impact of snow nitrate photolysis on boundary layer chemistry and the recycling and redistribution of reactive nitrogen across Antarctica and Greenland in a global chemical transport model. Atmos. Chem. Phys. 16, 2819-2842 (2016).

32. France, J. L. et al. Snow optical properties at Dome C (Concordia), Antarctica; implications for snow emissions and snow chemistry of reactive nitrogen. Atmos. Chem. Phys. 11, 9787-9801 (2011).

33. Wolff, E., Jones, A., Martin, T. \& Grenfell, T. Modelling photochemical NOX production and nitrate loss in the upper snowpack of Antarctica. Geophysical Research Letters 29, (2002).

34. Erbland, J. et al. Air-snow transfer of nitrate on the East Antarctic Plateau - Part 2: An isotopic model for the interpretation of deep ice-core records. Atmospheric Chemistry and Physics 15, 12079-12113 (2015).

35. Jiang, S. et al. Nitrate preservation in snow at Dome A, East Antarctica from ice core concentration and isotope records. Atmospheric Environment 213, 405-412 (2019).

36. Howat, I. M., Porter, C., Smith, B. E., Noh, M.-J. \& Morin, P. The Reference Elevation Model of Antarctica. The Cryosphere 13, 665-674 (2019).

37. Hui, F. et al. Mapping blue-ice areas in Antarctica using ETM+ and MODIS data. Annals of Glaciology 55, 129-137 (2014).

38. Savarino, J., Kaiser, J., Morin, S., Sigman, D. \& Thiemens, M. Nitrogen and oxygen isotopic constraints on the origin of atmospheric nitrate in coastal Antarctica. Atmospheric Chemistry and Physics 7, 1925-1945 (2007).

39. Servettaz, A., Landais, A. \& Orsi, A. Two thousand years of temperature variability on the lower East Antarctic Plateau inferred from the analysis of stable isotopes of water and inert gases in the Aurora Basin North ice core. (Université Paris-Saclay, 2021). 
40. Mouginot, J., Rignot, E. \& Scheuchl, B. Continent-wide, interferometric SAR phase, mapping of Antarctic ice velocity. Geophysical Research Letters 46, 9710-9718 (2019).

41. Le Meur, E. et al. Spatial and temporal distributions of surface mass balance between Concordia and Vostok stations, Antarctica, from combined radar and ice core data: first results and detailed error analysis. The Cryosphere 12, 1831-1850 (2018).

42. Stenni, B. et al. Eight centuries of volcanic signal and climate change at Talos Dome (East Antarctica). J. Geophys. Res.-Atmos. 107, 13 (2002).

43. Frezzotti, M., Scarchilli, C., Becagli, S., Proposito, M. \& Urbini, S. A synthesis of the Antarctic surface mass balance during the last 800 yr. The Cryosphere 7, 303-319 (2013).

44. Urbini, S. et al. Historical behaviour of Dome C and Talos Dome (East Antarctica) as investigated by snow accumulation and ice velocity measurements. Global and Planetary Change 60, 576-588 (2008).

45. Wille, J. D. et al. Antarctic atmospheric river climatology and precipitation impacts. Journal of Geophysical Research: Atmospheres 126, (2021).

46. Turner, J. et al. The Dominant Role of Extreme Precipitation Events in Antarctic Snowfall Variability. Geophysical Research Letters 46, 3502-3511 (2019).

47. Frezzotti, M., Gandolfi, S., Marca, F. L. \& Urbini, S. Snow dunes and glazed surfaces in Antarctica: new field and remote-sensing data. Annals of Glaciology 34, 81-88 (2002).

48. Libois, Q., Picard, G., Arnaud, L., Morin, S. \& Brun, E. Modeling the impact of snow drift on the decameter-scale variability of snow properties on the Antarctic Plateau. Journal of Geophysical Research: Atmospheres 119, 11662-11681 (2014).

49. Picard, G., Arnaud, L., Caneill, R., Lefebvre, E. \& Lamare, M. Observation of the process of snow accumulation on the Antarctic Plateau by time lapse laser scanning. The Cryosphere 13, 1983-1999 (2019).

50. Neubauer, C. et al. Stable isotope analysis of intact oxyanions using electrospray quadrupole-orbitrap mass spectrometry. Anal. Chem. 92, 3077-3085 (2020).

51. Meusinger, C., Berhanu, T. A., Erbland, J., Savarino, J. \& Johnson, M. S. Laboratory study of nitrate photolysis in Antarctic snow. I. Observed quantum yield, domain of photolysis, and secondary chemistry. The Journal of Chemical Physics 140, 244305 (2014).

52. Chu, L. \& Anastasio, C. Quantum yields of hydroxyl radical and nitrogen dioxide from the photolysis of nitrate on ice. J. Phys. Chem. A 107, 9594-9602 (2003). 
53. Benedict, K. B., McFall, A. S. \& Anastasio, C. Quantum yield of nitrite from the photolysis of aqueous nitrate above 300 nm. Environ. Sci. Technol. 51, 4387-4395 (2017).

54. Kaiser, J., Hastings, M. G., Houlton, B. Z., Röckmann, T. \& Sigman, D. M. Triple oxygen isotope analysis of nitrate Using the denitrifier method and thermal decomposition of N2O. Analytical Chemistry 79, 599607 (2007).

55. Morin, S. et al. Comprehensive isotopic composition of atmospheric nitrate in the Atlantic Ocean boundary layer from 65 degrees S to 79 degrees N. Journal of Geophysical Research-Atmospheres 114, (2009).

56. Sigman, D. M. et al. A bacterial method for the nitrogen isotopic analysis of nitrate in seawater and freshwater. Anal. Chem. 73, 4145-4153 (2001).

57. Casciotti, K. L., Sigman, D. M., Hastings, M. G., Böhlke, J. K. \& Hilkert, A. Measurement of the oxygen isotopic composition of nitrate in seawater and freshwater using the denitrifier method. Anal. Chem. 74, 4905-4912 (2002).

58. Baertschi, P. Absolute 180 content of standard mean ocean water. Earth and Planetary Science Letters 31, 341-344 (1976).

59. Mariotti, A. Atmospheric nitrogen is a reliable standard for natural $15 \mathrm{~N}$ abundance measurements. Nature 303, 685-687 (1983).

60. Pourchet, M. et al. Distribution and fall-out of 137Cs and other radionuclides over Antarctica. Journal of Glaciology 43, 435-445 (1997).

61. Ding, M. et al. Spatial variability of surface mass balance along a traverse route from Zhongshan station to Dome A, Antarctica. Journal of Glaciology 57, 658-666 (2011).

62. Verfaillie, D. et al. Snow accumulation variability derived from radar and firn core data along a $600 \mathrm{~km}$ transect in Adelie Land, East Antarctic plateau. The Cryosphere 6, 1345-1358 (2012).

63. Favier, V. et al. An updated and quality controlled surface mass balance dataset for Antarctica. The Cryosphere 7, 583-597 (2013).

64. Hoshina, Y., Fujita, K., Iizuka, Y. \& Motoyama, H. Inconsistent relationships between major ions and water stable isotopes in Antarctic snow under different accumulation environments. Polar Science 10, 1-10 (2016).

65. Ding, M. et al. Re-assessment of recent (2008 - 2013) surface mass balance over Dome Argus, Antarctica. POLAR 35, (2016). 
66. Ekaykin, A. A. et al. Underestimation of Snow Accumulation Rate in Central Antarctica (Vostok Station) Derived from Stake Measurements. Russian Meteorology and Hydrology 45, 132-140 (2020).

67. Sommer, S., Wagenbach, D., Mulvaney, R. \& Fischer, H. Glacio-chemical study spanning the past 2 kyr on three ice cores from Dronning Maud Land, Antarctica: 2. Seasonally resolved chemical records. Journal of Geophysical Research: Atmospheres 105, 29423-29433 (2000).

68. Richter, A. et al. Surface mass balance models vs. stake observations: a comparison in the Lake Vostok region, central East Antarctica. Frontiers in Earth Science 9, 388 (2021). 


\section{Supplementary Files}

This is a list of supplementary files associated with this preprint. Click to download.

- Akersd15NManuscript20220128NComSupplement.docx 